\title{
Soils and Fertilisers in South Africa.*
}

\author{
By Sir Frederick Keeble, C.B.E., F.R.S.
}

TTHE problems of South African agriculture which 1 await solution fall into two groups-those of arable and those of grassland. Of the two, the problems of grassland are potentially of greater importance.

\section{Grassland.}

The grasslands of South Africa are poor and barren. Over vast areas the scant herbage serves scarcely to cover the ground even during the growing season. It turns brown and grows yet scarcer during the dry season. There are green hills in Natal and green pastures, and even in regions of low rainfall after summer showers the brown herbage grows green again. There are large areas of grassland in which the spring herbage is luxuriant and nutritious, but as spring advances the feeding value of the grass declines and cattle have often to submit and succumb to conditions of starvation.

It seems to be universally assumed that this state of affairs is due to lack of water and that it can best be remedied by introducing from other countries grasses of greater powers of resistance to drought. Much work of great interest along these lines, both on irrigated and non-irrigated land, has been done in South Africa, particularly by Dr. Pole-Evans at Pretoria. He has shown that it is possible to establish many grasses from other parts of the world and to obtain large amounts of food for stock from them. But the suggestion which has now to be made casts doubt upon this method as being the most important means of rejuvenating the pastures of South Africa. This suggestion is that many of the troubles attributed to drought are more properly to be ascribed to mineral deficiency. The hunger of the soil for phosphates is only one symptom, albeit a most important symptom, of these deficiencies. The land, or much of it, also lacks lime, and although the lack is well known, little is being done to remedy it. Yet lack of lime may prove to be a limiting factor of yield on both arable and grassland. Many officials maintain that the addition of lime depresses yield, and fail to consider that this in itself may be a passing symptom of a deep-seated trouble and want. It is encouraging therefore to report that both in Natal (Cedara) and in Rhodesia (Salisbury) experiments are now being carried out which point to benefits from liming.

With an insufficiency of lime and phosphates in the soils the herbage must perforce be deficient in these essential materials; the yellow or pale green colour of the grass betokens that it lacks nitrogen; and it is certain that there are also deficiencies in potash. What other deficiencies there are of other more obscure elements which may prove to be important only further research will show.

It is suggested that all these deficiencies have been brought about by simple cosmic processes.

South Africa is the stem of a funnel, the mouth of which is the equator. Of all that teeming life bred in the warmth and moisture of the tropies there must from time to time, as bees swarm, have migrated hordes of all kinds of animals. Debarred by the desert from invading the north, these migrant hordes have gone ever southward. Sometimes the grasslands which these migrants invaded were lush with spring grass and sufficed to feed the beasts; but at other times when the sun was fierce in summer and the growth of grass stood still, there was lack of

* From a paper read before Section M (Agriculture) of the British Association at Bristol on Sept. 5.

No. 3176 , VoL. 126] herbage. Thus pushed by hunger the herbivora grazed the pasture bare to the bone. The grass over-grazed became worn and thin. Like a garment too much used, the herbage became rent, and through the rents rains, often of torrential violence, pierced and swept away the soil, aggravating the effects of over-grazing. So the vicious circle was completed and remains complete to the constant impoverishment of South African soils.

Any traveller in the Union may see the rivers leap to life in the rains which attack the earth, carve it out and bear it away, and run red with the soil washed from the land. He may likewise see in the veldt-burning practised by farmers yet another aid to soil impoverishment: for though burning brings young and sweet and early grass, the partial sterilisation of the soil which it produces releases the little store of hardly won organic nitrogen which is absorbed greedily by the young grass in the flush of its spring growth. The soil is soon depleted, so that long before drought imposes its veto, growth wanes and the veldt becomes brown and bare and barren. Flocks and herds are decimated, and the patient farmer praying for rain fails to realise that he himself offered them as a burnt-offering to the god of ignorance.

Under these conditions of over-grazing and erosion an age-long struggle for existence must have waged among the plants of South African grassland, and the struggle must have been of ever-increasing intensity as the soil became more and more depleted of its mineral contents and its nitrogen compounds. In this struggle those grassland plants with larger requirements of minerals and of nitrogen were the first to succumb. They ceased to be members of the grassland community but, retiring from the unequal struggle, continue to survive here and there in those favoured mineral oases wherein their larger mode of life finds satisfaction. The struggle is still going on, and now only the most niggardly of the plants, mean in what they get and what they give, survive. Except for a brief period in the flush of spring they yield but little sustenance to the animals which graze upon them.

If this picture of the evolution of the grassland of South Africa be true, conclusions of fundamental importance follow. The first of these conclusions is that the restoration of South African pastures is possible. The second conclusion is that the way of improvement lies in the restoration to the soil of conditions under which plants of larger requirements and higher nutritive value may live. The third conclusion is that the picture of the decadence of grassland in South Africa, although more vivid, is none the less identical with the, albeit more drab, picture presented by the world as a whole. The factor which has determined the trend of evolution in this as well as in earlier geological epochs is the decreasing supply of minerals stored in the grasslands and arable fields of the world.

Deficiency of nutritiveness of the plants of arable crops means deficiency of nutrition in man and beast, which in turn means disease, and it may be that the wealth of animal diseases which Africa possesses is but another symptom of the gradually lowered vitality of living things due to gradual decrease in the supply of essential minerals.

If this be true, then in grassland management with its insistence on the restoration of minerals there are means of arresting the downward trend of evolution, or at least of slowing down the rate at which nitrogen 
and phosphorus escape, the one into space, the other into the abysms of the ocean.

Whether these large conjectures prove true or no, the first two conclusions require brief consideration. If it be true that a restoration of minerals to the soil brings about a return of plants of good grazing value, we shall have a most important vindication of intensive grassland management. For the general principle underlying the intensive management of grassland is that conditions may be provided wherein more nutritive native and introduced plants will flourish. That it will prove possible to transform the grassland of South Africa is rendered probable by the remarkable results which Mr. T. D. Hall's small scale experiments on grassland in different parts of South Africa have already achieved.

These experiments show :

(1) That grassland in South Africa responds in an almost magical way to nitrogen.

(2) That the relation between nitrogen and phosphates which obtains in grassland is the reciprocal of that which obtains on arable land. Though a dressing of phosphates adds but little growth to that produced by a single dressing of nitrogen, a dressing of phosphates added to a double dressing of nitrogen brings about a marked increase. The explanation would appear to be that the grassland plants surviving to-day are able to extract even from the impoverished soil just enough phosphates to live on ; but in that grassland there is not enough nitrogen to go round, and so growth languishes until additional nitrogen is supplied. Addition of more nitrogen produces little effect. Addition of more phosphates as well as more nitrogen gives rise to a further increase in growth.

(3) The treatment of grass with a complete fertiliser together with lime gives the largest response.

These experiments suggest the conclusion that a brilliant future awaits South African grassland. It is even safer to conclude from them that our knowledge of the proper fertiliser treatment of grassland is only just emerging from the empirical into the scientific stage, and that the investigation of the nitrogenphosphate balance with potash in attendance will lead to the discovery that grass can be made far more productive than is at present supposed.

The opinion that grass will play an important part in the future of South African agriculture is reinforced when South African rainfall is considered. Much of South Africa is a land of summer rainfall. Grass is the opportunist among plants ; it grows during growing weather and dies down when conditions are unfavourable to growth. A drought may cut off an arable crop in its prime, but it can rarely do more than check the growth of grass. Experiments now being conducted in Natal, at the Cedara School of Agriculture, lend confirmation to the view that grassland in South Africa will respond to intensive management no less readily than the grassland in Great Britain. Mr. R. A. Fisher's experiments show that even a grass (Paspalum sp.) reputed by farmers to be of low grazing value, responds to fertilisers so remarkably as to produce enough food during the grazing season to enable one cow to yield 1000 gallons of milk.

One more suggestion may be made with respect to nitrogen on grassland. Owing to the intensity of the struggle for existence, grassland plants must always be hungry for nitrogen. Such nitrogen as grassland contains, and for which the plants have perforce to scramble, is derived from the breaking down of organic nitrogen compounds. The breaking down proceeds by orderly stages until compounds of ammonium are formed. The nitrifying bacteria then convert the ammonia first into nitrites and then into nitrates. It is usually believed that all plants of grassland, hungry as they are for nitrogen, wait passively until nitrate is formed before they attempt to supply their wants. It would seem more likely, however, that with capacities sharpened by the struggle, there would emerge from among some of the grasses the capacity to absorb nitrogen in the form of ammonia, or even in organic form, and such plants would be victorious in the struggle for existence. It may therefore be predicted that amongst grassland plants, some at all events may be found which possess the power of obtaining nitrogen in the form of ammonia, and it may prove that the grass family is distinguished from other plants by this capacity.

The dicotyledons, including the common weeds of pastures, can obtain nitrogen only in the form of nitrates, and to them ammonium compounds are poison. But the grass plants are able to utilise and thrive on the nitrogen obtained in the form of ammonia. Two facts support these suggestions. The first is that sulphate of ammonia and ammonium phosphates have a lethal effect upon the common weeds of grassland; the second, that sulphate of ammonia is at least the equal of nitrate nitrogen in calling forth the growth of grassland in spring. This equality is difficult to explain if the common view be accepted that before ammonia can be utilised by the plants it must first be converted into nitrates.

The power of sulphate of ammonia to evoke early growth of grass would be self-evident were it to be proved that ammonium compounds are the proper nitrogenous food for grass, and, needless to say, such proof should be of great value. Of no less value should be the proof, if it can be obtained, that ammonium phosphate is the right fertiliser to use on a plant which responds markedly to a proper balance of nitrogenous and phosphatic fertilisers.

\section{Arable Land.}

The arable crops of South Africa are poor. The yield of maize in the Union is on the average three bags to the acre, that is, about one-third of a crop even when measured by American standards. Poor cultivation is in part responsible for low yields, far more so indeed than seems to be realised in South Africa. Other limiting factors are water and phosphaticdeficiency, and it is a general obsession in South Africa. that most of the agricultural troubles from which that country suffers are due to lack of water. Science should aid effectively in curing this obsession. It has. already shown that in spite of low rainfall, crops can be produced if the deficiency of the soil in phosphates be made good. But even after applications of phosphates the crop remains small, and the expert attributes the low yield to insufficiency of water. In this he is partly, albeit only partly, right. When he adds nitrogen on the top of his phosphates the result is often disappointing, and he draws the conclusion that nitrogen, by encouraging the growth of leaf and stem and thereby increasing the loss of water from the plant by transpiration, does more harm than good by making the limited amount of water in the soil still more insufficient. For this reason the expert. and the farmer avoid using nitrogen. Sometimes an additional reason is advanced; namely, that nitrification goes on so quickly in South African soils that there will always be enough nitrogen available when the plant needs it.

The latter explanation may be considered briefly and dismissed. South African soils are desperately poor in organic matter. Organic matter is the sole. source of supply of natural nitrogen. If the source

No. 3176, VoL. 126] 
of supply of natural nitrogen is almost non-existent, to believe that nitrification can supply enough nitrogen to the plants is to believe in the making of bricks without straw; albeit that it is possible to hold, as has been suggested, that the plant residues in the soil supply just enough material to permit of an amount of nitrogen fixation sufficient, and no more than sufficient, to make good the annual loss through nitrification.

The extreme poverty of South African soils in humus and the essential part which organic matter plays in the feeding of crops are facts which those interested in the use of fertilisers must take into careful consideration. Observations in South Africa have led me to propound some ideas which may throw light upon the rôle which organic matter plays in the soil. Hitherto it has been believed that the chief virtue of organic matter, apart from its physical effect on the soil, lies in the nitrogen which it supplies. Experiments made in South Africa on irrigated land are claimed by their authors to show that, whereas the addition of inorganic nitrogen produced no increase in crops, the addition of even so small an amount as 1 ton per acre of Kraal manure brings about marked crop increase. It is difficult, although perhaps not impossible, to believe that a small quantity of nitrogen in organic form is more beneficial to plants than a larger quantity of inorganic nitrogen. It is more reasonable to seek the benefit of the Kraal manure in the carbon which it contains, and it may be conjectured that the chief chemical rôle of organic matter is to supply carbon for the soil bacteria, and particularly for thosesoil bacteria which are engaged in nitrogen fixation. This consideration suggests a line of research of practical importance. If carbon in organic form be proved to play such an important part in enhancing soil fertility, it may become necessary to use as a 'filler' in the manufacture of complete fertilisers some cheap waste product rich in organic carbon. There are expert growers, some of them among the best in the world, who act empirically as though they held this view and use always large amounts of organic matter together with artificials in order to produce large crops of fruit and vegetables.

Considerations of the bacterial changes in the soil lead to yet a further suggestion; the wattle growers in Natal have proved that phosphates give a much larger growth of the tree than is obtained without their use. Now in a fairly wide excursion throughout South Africa, one of the few signs of nitrogen plenty was shown in the green-black colour of the leaves of wattles treated with phosphates. The dark colour suggests that the wattles have received plenty of nitrogen. But the soil is poor in nitrogen. Therefore the trees must have obtained it from the nitrogenfixing nodule organism which infects the roots.

Inquiry showed that on the roots of the phosphatetreated trees the nodules are far larger than on the roots of trees without added phosphates. Phosphates are known to encourage nitrogen-fixing bacteria, but it is now suggested that these latter organisms are no less intimately connected with phosphates than they are with nitrogen; in other words, that they not only bring nitrogen from the air into organic combination, but also that they do the like for the phosphates of the soil. If so, these nitrogen-fixing soil bacteria are the foundation-stones of soil fertility and their prevalence is determined first by the supply of organic carbon in the soil, and secondly by the supply of phosphates.

In support of this suggestion it may be mentioned that the nodule-forming nitrogen-fixing organism of clover is said to possess the power (denied to other grassland plants) of obtaining its phosphates from insoluble sources - a belief which could be easily verified. If it be true, it should be possible to balance, as a juggler does balls, the clovers and grass constituents of a pasture by supplying phosphates now in soluble now in insoluble form. If this possibility were achieved it would have great practical value. All these things considered, it may prove that al though South African soils are at present poor, their defects can be gradually remedied by the systematic use of fertilisers containing nitrogen and all the essential mineral elements as well as carbon compounds in a suitable form.

Another and extraordinary fact lends confidence to this prediction. Trees of many kinds and in the different States of the Union-Natal, Orange Free State, and Transvaal-grow with far greater vigour than they do in Europe. This fervour of growth is attributed in South Africa to water. It cannot be for water could at best make the trees grow only as fast as they grow in Europe and not faster. Therefore among contributing causes to the vigour of growth not the least must be larger supplies of minerals. Unlike surface-rooting plants, trees can dive deep in the soil and from the deepest layers recover the phosphates which have vanished from the surface.

Lastly, there remains to consider the second of the two alternatives already mentioned in explanation of current failure of nitrogen to give increased crop production on land treated with phosphatic fertilisers; this suggestion may be stated thus. The amount of phosphates given to crops is $200 \mathrm{lb}$. to the acre -an extremely light dressing. The soils of South Africa are desperately hungry for phosphates. There is no reason to suppose that $200 \mathrm{lb}$. per acre satisfies their needs, especially for such a phosphate-greedy crop as maize.

Lack of 'phosphates may still be limiting crop production, and if so the addition of nitrogen would certainly do more harm than good. A double dressing of phosphates is known to give further increase of crop yields, but there is no reason why even a double dressing should completely make good phosphatic deficiency. There is evidence that $800 \mathrm{lb}$. or $1000 \mathrm{lb}$. to the morgen goes on increasing yields; and it is therefore suggested that the fundamental experiment is one in which a phosphate-needing plant (for example, maize) is grown in a series of soils which receive from $200 \mathrm{lb}$. to $1200 \mathrm{lb}$, or more, per acre together with a uniform light dressing of inorganic nitrogen, in order to ascertain whether when phosphate deficiency is completely remedied, nitrogen does not begin to come into beneficent operation.

With that experiment should be made an inquiry into the morphological effect of phosphates, that is to say, the effect of phosphates on modifying the relative growth of the root system and the shoot system. Phosphates are known to encourage root growth. It is suggested that with progressive increases in phosphates root growth may be more and more increased with the corresponding discouragement of stem growth. That would mean that the plant becomes both a more and more efficient collector and a greater and greater economiser of water. For with increased root more water is absorbed, and with reduced leaf and stem loss of water from the plant is reduced. If this proves indeed to be the case, then a changed technique might vindicate nitrogen as a crop producer in the dry soils of South Africa. The change would consist in regulating the amount of nitrogen in relation to the phosphates and in applying it as a top-dressing after development has proceeded to a certain extent, and not as at present with the seed. Along with this series of experiments there should be another which would analyse more

No. 3176, VoL. 126] 
completely than has yet been done the well-established fact that fertilisers increase water economy in the growing plants. It has been shown in India and elsewhere that when fertilisers are supplied to plants economy in the production of dry matter is increased. But at the same time the total amount of dry matter may be so increased as to make more demands upon the soil water-supply than are made by the plant which receives no fertilisers. One of the most important problems before scientific agriculture must therefore be a working out of the most water-economising ration of artificials to be supplied to different kinds of plants.

There are also experiments to be made in discovering varieties of maize and corm which will respond to fertilisers more effectively than those now grown, and there are also other genetical experiments which need to be carried out designed to discover races with male inflorescences which will continue to produce pollen over a long period, so that even if drought comes there may still be some pollen left after rain has restored growth to the plant.

There are other experiments of no less essential importance in relation to liming-a practice which is neglected in South Africa-and there are yet others : to seek in carbon fixation carried on in uncropped soils the origin of the amazing renewal of fertility which fallowed fields display.
This sketch of the scientific problems which await solution shows incidentally how elosely the future of the industry of agriculture depends upon the advances of pure science, and suggests how important it is for that industry both to encourage the investigations and to take part in them.

I found South Africa in large part barren land; if the ideas with which it has inspired me are true, they may yet make it fertile. I myself believe that a great future lies before that country, for I think that on those high uplands so near the skies and so richly irradiated by the sun the plants and the animals derive greater sustenance from the irradiated foods than do the animals of lower altitude and lesser suns. I believe, moreover, that in that great mineral deficiency which has been described lies the original source of all those troubles which South Africa endures. It is, I believe, defective nutrition that has brought in its train the many maladies which afflict man and beast. If so, when the grass is restored to its full vigour animals will renew their youth and defeat the attacks of now victorious parasitic pests. On those parts of South Africa from which those parasites are banished the trees grow stronger than they do elsewhere, the men and women are sturdier, and even the flowers are more exuberant and more substantial than they are when we grow them under our sadder skies.

\section{Anthropology-Old and New.*}

$\mathrm{W}$

HEN we look back to the times in which Dr. Beddoe lived and worked and note the doings of the men who were searching into the beginnings of the British people, we see that we owe more to him than to any other anthropologist of the Victorian epoch. It was he who laid our present knowledge upon a sure basis. He set out in his youth to find an answer to an age-old query: Of what race or races are we British ?

Dr. Beddoe was born in Galton's 'brain-belt', which, passing from Liverpool to Swansea, includes the English counties bordering on Wales. Bristol is indebted to this belt for many of her most distinguished citizens. It gave her Dr. James Cowles Prichard, who made England famous in the annals of anthropology in the first half of the nineteenth century. This belt coincides with an old ethnological frontier across which Saxon and Celt have freely exchanged their heritage of blood; and it was their place of birth which turned the minds of Prichard and Beddoe to the problems of race.

Beddoe while still living in his father's house at Bewdley listened to discussions concerning the Celts, especially as regards their colouring. No one, he discovered, had made a census of the colouring of the people called Celts or of any other race of mankind. $\mathrm{He}$ determined to investigate the colouring of the British races by exact methods. He entered into a virgin field of investigation, and it was necessary for him to invent methods of making records of colour of hair, eyes, and complexion. He began his investigations at the age of twenty, and visited Ireland, Wales, the Highlands of Scotland, the Orkneys and Shetlands, and France in the pursuit of his investigation. The Crimean war, in which he served as a medical man, and a subsequent period of study at Vienna gave him the opportunity of observation in the Baltic, the Near East, Croatia, Styria, and Italy. When he settled down to practise in Bristol in 1857 there was no one in Europe had his exact knowledge of the western peoples. There was not a single year between 1857 and 1891, when he *Abstract of the Beddoe MemoriaI Lecture delivered by Sir Arthur
Keith, on Sept. 5 , in connexion with the Bristol meeting of the British Keith, on Se
Association.

No. 3176 , VoL. 126] retired to Bradford-on-Avon, that Dr. Beddoe did not carry out an anthropological raid of some kind-on the Continent, or in Ireland, Wales, Scotland, or England.

There was another side to Dr. Beddoe's inquiries. There were many in Dr. Beddoe's day who feared that industrialism would ultimately undermine the health and strength of the people of England; but he was one of the few to pass from speculation to actual inquiry. So he set himself to measure height, weight, size of head, colour of hair and eyes, not only of every stratum of the population of Bristol, but also of the open-living inhabitants of surrounding counties. From his results there emerged a suspicion that city life was shortening stature and favouring the lighter rather than the darker haired types.

Beddoe was the first to ascertain how city life affects racial types. He found that far from the type becoming uniform under the influence of city life, there was a tendency to segregation of types: the racial traits which prevailed among business men were not those which marked the artisan. In the selection of their mates, the men of Bristol preferred blondes to 'reds' and 'blacks'. Disease and conditions of industrial life, on the other hand, favoured those who had a dark complexion rather than those who were fair-skinned. Emigration was selective; it tended to rob Bristol of its best. Beddoe perceived that the effects produced by city life on the body and mind of man presented problems which could be solved only by patient and careful inquiry. It is this side of Beddoe's pioneer labours which needs to be stressed. We cannot be comfortable concerning our future until we know what is happening to us. A city population cannot stand still. The medical officer keeps his finger on the pulse of public health; there should be an anthropologist to keep his finger on the pulse of type-physical and mental. Beddoe's work on the population of Bristol should find its logical outcome in the institution of a chair of physical anthropology in the University of Bristol.

Dr. Beddoe devoted the spare time of his manhood to amassing data concerning the colouring and other physical traits of the peoples of western Europe- 